\title{
Compsodactylus Fuhrmann, 2012 (Coleoptera: Scarabaeidae: Melolonthinae): distributional notes and a new species
}

\author{
JUARES FUHRMANN ${ }^{1} \&$ ANDREW B.T. SMITH ${ }^{2}$ \\ ${ }^{1}$ Museu de Zoologia da Universidade de São Paulo, 04218-970 São Paulo-SP, Brazil. \\ "”jufuhrmann@gmail.com; (1) https://orcid.org/0000-0002-1617-254X \\ ${ }^{2}$ Canadian Museum of Nature, P.O. Box 3443, Station D, Ottawa, Ontario, K1P 6P4, Canada. \\ झ"asmith@unl.edu; 이ttps://orcid.org/0000-0002-8059-5133
}

\begin{abstract}
A new species of Compsodactylus Fuhrmann, 2012 (Coleoptera: Scarabaeidae: Melolonthinae: Macrodactylini) is described from Peru. New provincial records for Compsodactylus argentinus (Moser, 1919) are detailed for Argentina: Córdoba and Misiones. A revised key to Compsodactylus species is presented.
\end{abstract}

Key words: Macrodactylini, Argentina, Peru, Neotropics, taxonomy

\section{Introduction}

The genus Compsodactylus Fuhrmann, 2012 (Coleoptera: Scarabaeidae: Melolonthinae: Macrodactylini) was recently described (Fuhrmann 2012) and there were two subsequent papers describing a new species and refining the taxonomy (Figueroa \& Neita-Moreno 2019; Fuhrmann 2019). While working on the material in the Florida State Collection of Arthropods (FSCA; Gainesville, Florida, United States of America), we discovered a new species from Peru. We also discovered two new provincial records in Argentina for Compsodactylus argentinus (Moser, 1919) in the Canadian Museum of Nature collection (CMNC; Ottawa, Ontario, Canada). The purpose of this paper is to record the new distributional data, describe the new species, and present a revised key to species of Compsodactylus.

\section{Methods and materials}

Morphological characters form the basis of present study. Terminology used for the morphological characters follows Beutel \& Lawrence (2005) and Lawrence et al. (2010). Illustrations were produced using camera lucida attached to a Wild stereomicroscope. Photographs were taken with a Leica Z16 APOA microscope and processed using Leica Application Suite (LAS) 4.2. The terminalia were studied using dissected specimens by relaxing the parts in hot water. Detached parts were card mounted with acid-free, water-soluble glue. Label data for type specimens is given verbatim with the "/" indicating a line break in the text.

The geographic data were digitalized using Google Earth (www.google.com/earth) and maps were created using QGis (version 2.18, https://qgis.org/en/site). The plates were edited using Adobe Photoshop Cs6 (www.adobe. $\mathrm{com} / \mathrm{ca} /$ products/photoshop.html).

\section{Compsodactylus argentinus (Moser, 1919)}

Material examined (all from the CMNC). ARGENTINA: SALTA: Departamento Capital, Villa San Lorenzo, ii.1988, 1 male; Coronel Moldes, ii.1945, Francisco Monrós (collector), 2 males, 1 female; La Viña, ii.1992, 2 males; Departamento La Viña, La Viña, i.1991, M.A. Viana (collector), 1 male, 1 female; Departamento La Viña, Ruta 68, 
4 km S La Viña, i.1988, 10 males, 7 females; Departamento La Viña, El Carmen, ii.1993, 25 males, 10 females; Departamento La Viña, El Carmen, iii.1993, 7 males. Catamarca: Campo del Arenal, ii.1983, L. Peña (collector), 8 males, 5 females; Santa Maria Village, $26^{\circ} 41^{\prime}$ S, 66 $02^{\prime}$ W, 14.ii.1983, 3 males; Chafiñan, Weiser (collector), 2 males, 1 female. Misiones: Departamento Capital, Itaembé Miní, iv.1993, M.A.F. (collector), 2 males. Tucuman, San Pedro de Colalao, i.1947, P. Arnau (collector), 2 females. CordobA, Departamento de Calamuchita, Cañada del Sauce ("El Sauce"), xii.1938, Manuel J. Viana (collector), 2 males.

Distribution (Fig. 26). New provincial records were discovered as follows. Argentina: Córdoba: Departamento de Calamuchita: "El Sauce"; Argentina: Misiones: Departamento Capital: Itambé Miní. This species was previously known from Catamarca, Salta, and Tucumán in Argentina.

Note. Fuhrmann (2019) noted that the pronotum of Compsodactylus parvulus (Frey, 1970) is dark brown and sometimes the lateral angles and posterior margin have yellow maculae. This same pattern was observed in some specimens of $C$. argentinus.

\section{Compsodactylus mendax Fuhrmann \& Smith, new species}

(Figs. 1-8, 15-16, 19-26)

Type material. Male holotype (FSCA, Figs. 1-4), allotype (FSCA, Figs; 6-8), and male paratype (CMNC) all labeled (Fig. 5): "PERU: Dept. Lima / Sta. Eulalia 1035m / 30-31 Mar 2011 / J.B. Heppner \& C. Carrera". These specimens also have our corresponding red holotype and allotype labels and yellow paratype label.

Diagnosis. Length greater than $8.0 \mathrm{~mm}$; dorsal surface with metallic green reflections; antennae with 10 antennomers; clypeus elongate with expanded apex in males (Fig. 4); clypeus with short, spiny setae along apex and lateral edges in males; apex of protarsomere I 2 times wider than apex of protarsomere II in males; elytral striae distinctly punctate; male metatibial apex with an inner truncate, twisted process (Fig. 16); genitalia of females with gonostyle, and gonocoxite about 2.5 times longer than wide (Figs. 23-25).

Holotype description. Length $9.0 \mathrm{~mm}$, width $4.0 \mathrm{~mm}$ at the middle of elytra. Dorsal and ventral surface of head and thorax (except lateral edges of pronotum) black with metallic green reflections (Figs. 1-4); dorsal surface of elytra and lateral edges of pronotum yellowish brown with light metallic green reflections; ventral surface of abdomen shiny reddish brown, ventrite VI with anterior dark stripe; legs bicolored, reddish brown with dark sections and markings. Head with clypeus elongate, strongly expanded at apex (Fig. 4), surface glabrous medially and with short, spiny setae along apex and lateral edges. Frons surface with rugose punctures and densely setose, setae long, thin. Interocular distance 5 times wider than dorsal eye width. Antenna with 10 antennomeres, club longer than antennomeres II-VI combined. Pronotum surface rugose with long, dense setae, anterior margin with some minute, spiny setae. Elytra surface with moderately dense setae, striae distinctly punctate. Pygidium and ventral surface with dense punctures and hair-like setae. Protibia with 2 outer teeth, protarsomere I greatly enlarged with a padlike granulate ventral surface. Metafemur not strongly enlarged (about 2.1-2.4 times longer than wide, Fig. 15), inner margin without spines or carina and with some spiny setae. Metatibial apex with an inner, twisted process; metatibial spurs absent (Fig. 16).

Variation. The allotype is $8.5 \mathrm{~mm}$ in length with the following sexually dimorphic characters: clypeus not elongate, without glabrous area, and with apex subquadrate, not expanded; frons with short, spiny setae; protarsomere I cylindrical, not enlarged; metatibial apex without inner process and with 2 spurs. Female terminalia bearing a pair of elongate paraprocts; gonocoxite about 2.5 longer than wide and divided in a proximal and a distal piece; a lateral plate between paraproct and proximal piece of gonocoxite is present, gonostyle present (Figs. 23-25). The elytral suture is yellow in holotype and black with metallic green reflections in the allotype and paratype.

Distribution. The holotype, allotype, and a single paratype were collected in Santa Eulalia, Lima Department, Peru (approximately $11.902^{\circ} \mathrm{S}, 76.666^{\circ} \mathrm{W}$ ) at $1035 \mathrm{~m}$.

Etymology. From the Latin mendax meaning liar, in reference to the elongate clypeus being reminiscent of Pinocchio's nose. This name is a noun in apposition.

Remarks. Compsodactylus mendax new species is easily distinguished from the other four species in the genus because the clypeal apex is enlarged in males while the other species have a trapezoidal clypeus (Fig. 4); the dorsal surface has green metallic reflections and antennae have 10 antennomeres in females, a character combination not found in other species. Compsodactylus mendax is similar to C. martinezi (Frey, 1972) and C. vallejoi Figueroa \& Neita-Moreno, 2019 in that all three species have the apical spine of metatibia thick and projecting perpendicular 
to length of the tibiae in males (Figs. 13-18) and females have gonostyles. Compsodactylus argentinus and $C$. parvulus differ from these three species in that the apical spine of metatibia is thin and projecting parallel to the length of the tibia in males (Figs. 9-12) and females do not have gonostyles.
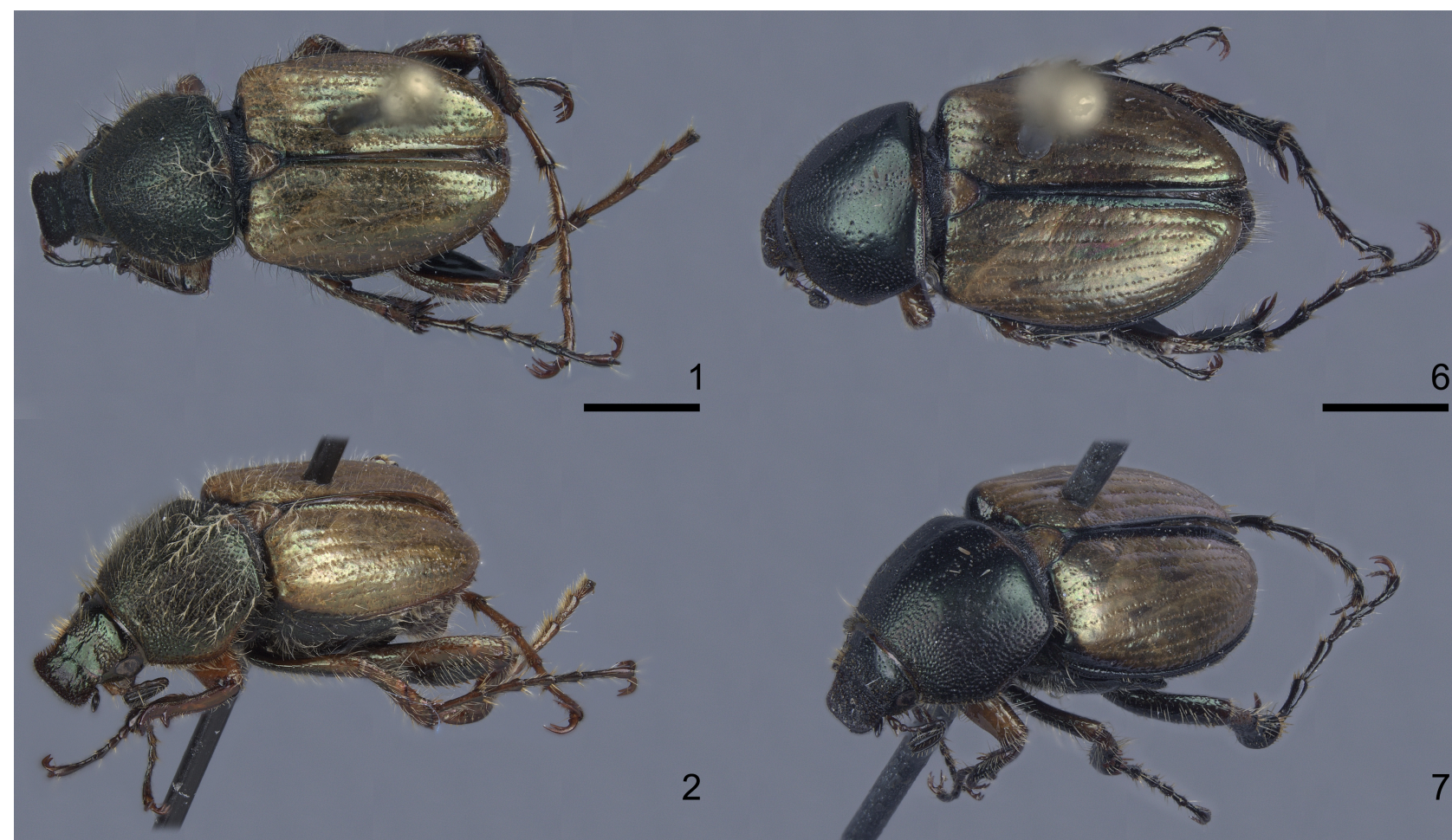

2
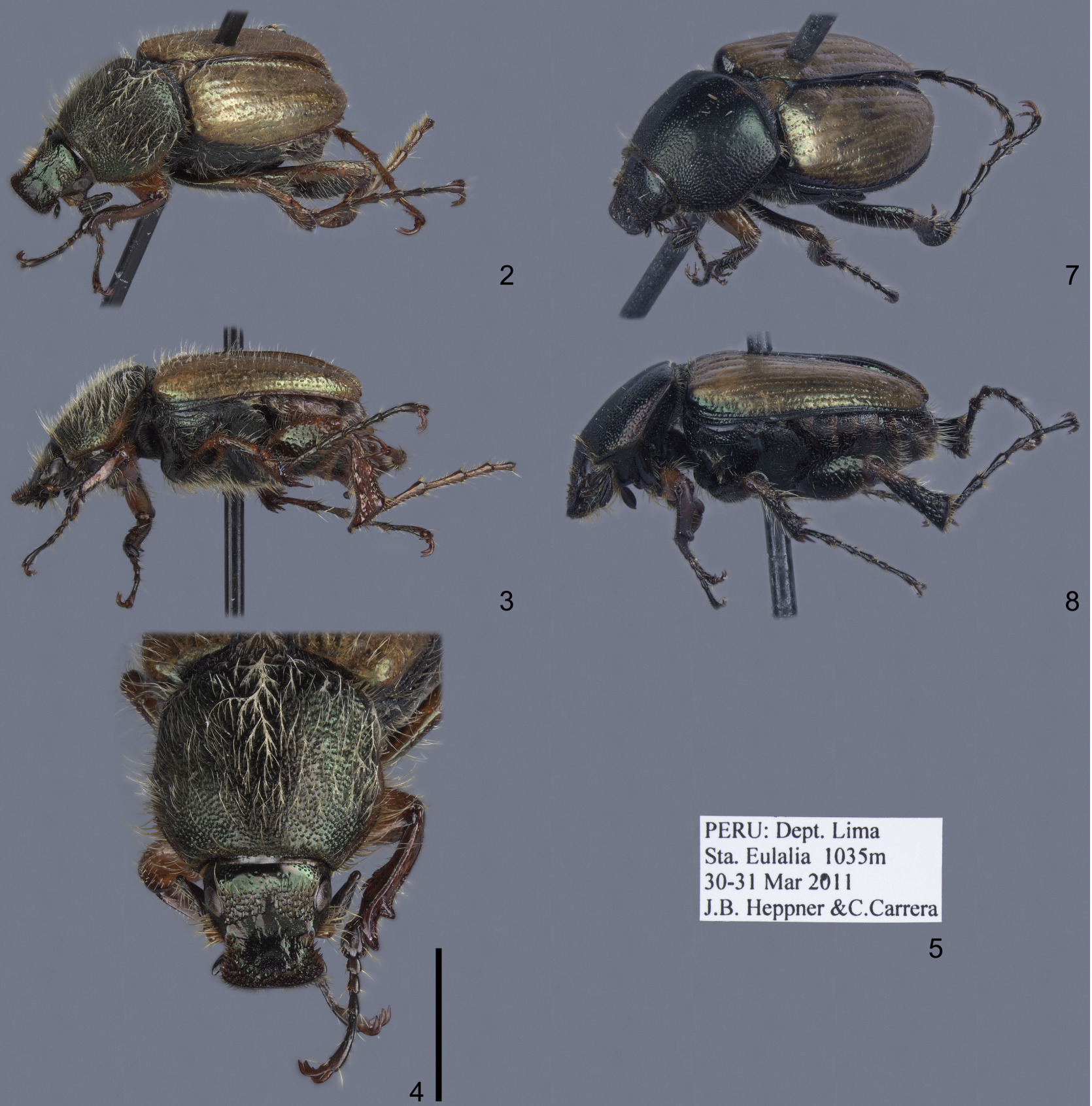

PERU: Dept. Lima

Sta. Eulalia $1035 \mathrm{~m}$

30-31 Mar 2011

J.B. Heppner \&C.Carrera

5

FIGURES 1-8. Compsodactylus mendax new species; 1-5, male holotype (dorsal, dorsolateral, lateral, dorsofrontal, label); 6-8, female allotype (dorsal, dorsolateral, lateral). Scale $=1.0 \mathrm{~mm}$. 


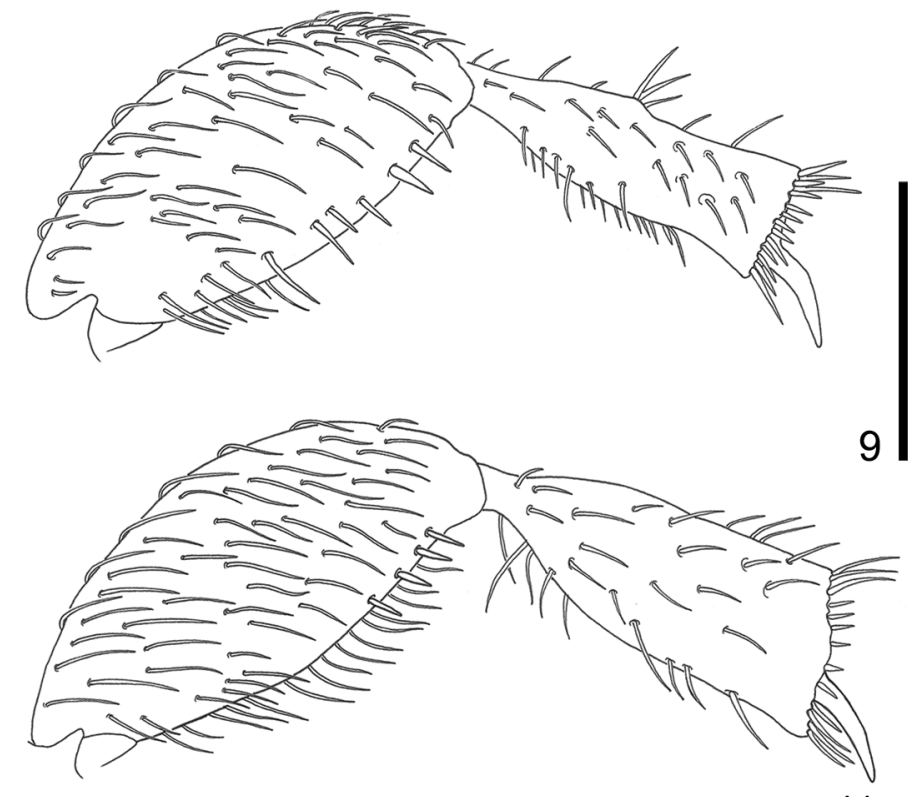

11
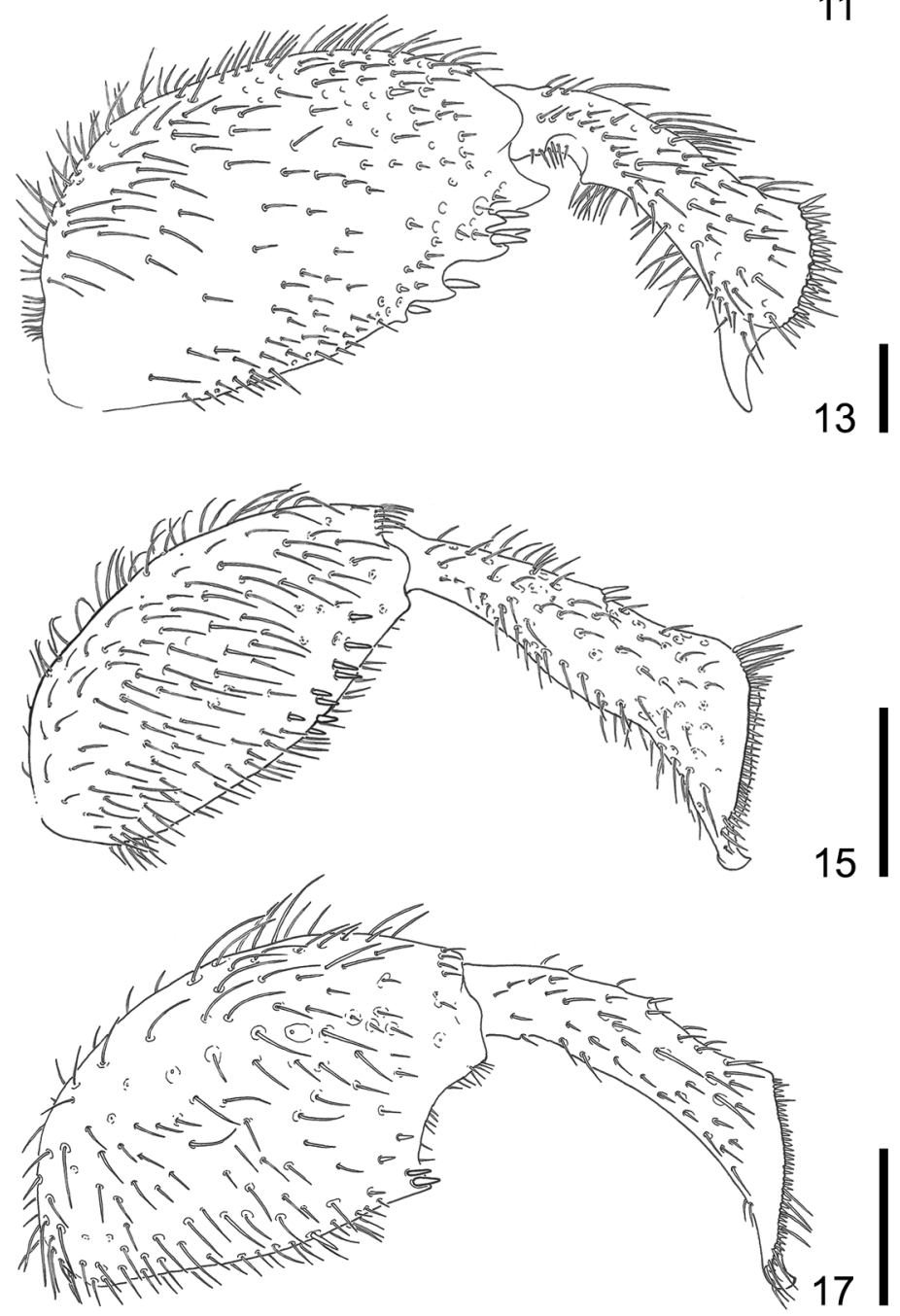
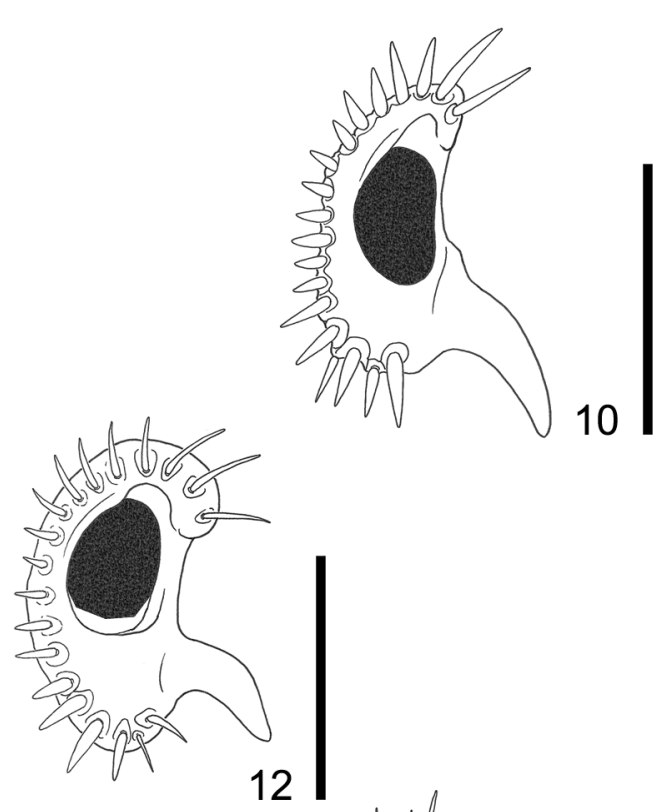

12

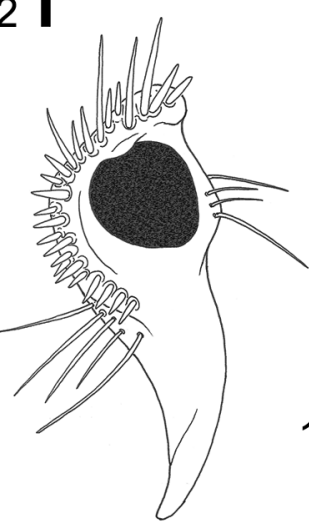

14

FIGURES 9-18. Compsodactylus, posterior leg of males; 9-10, C. argentinus (femur-tibia, apex of tibia); 11-12, C. parvulus (femur-tibia, apex of tibia); 13-14, C. martinezi (femur-tibia, apex of tibia); 15-16, C. mendax new species (femur-tibia, apex of tibia); 17-18, C. vallejoi (femur-tibia, apex of tibia; modified from Figueroa \& Neita-Moreno 2019). Scale $=1.0 \mathrm{~mm}$. 

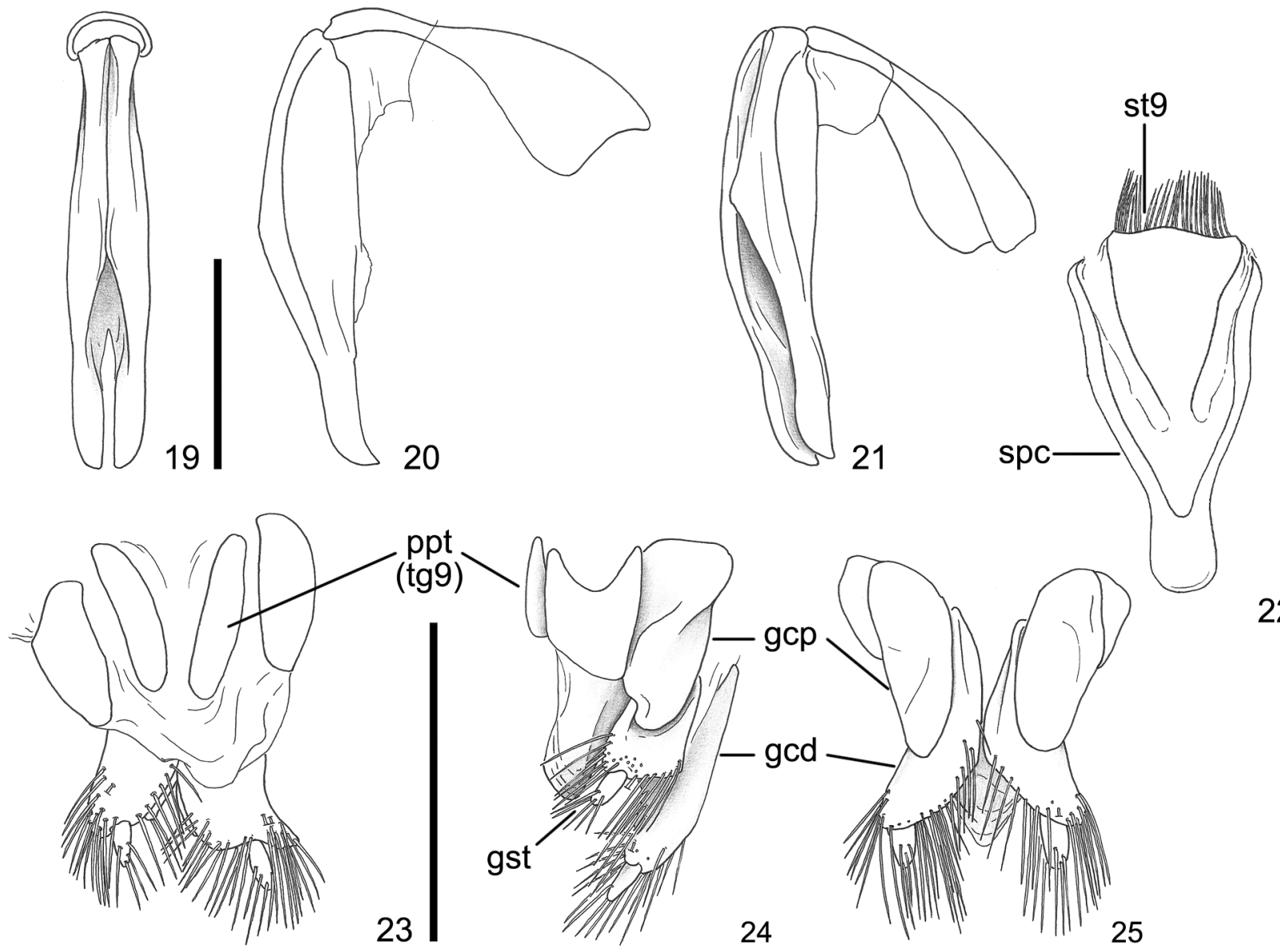

22

FIGURES 19-25. Compsodactylus mendax new species; 19, parameres, distal; 20-21, aedeagus (lateral, laterodistal), 22, genital ring of males; 23-26, terminalia of females (dorsal, lateral, ventral). ged, distal piece of gonocoxite; gcp; proximal piece of gonocoxite; ppt, paraprocts; gst, gonostyle; spc, spiculum gastrale; st9, abdominal sternite IX; tg9, abdominal tergite IX. Scale $=0.5 \mathrm{~mm}$.

Compsodactylus mendax is distinguished from C. martinezi and C. vallejoi by (characters of 1-C. martinezi and 2-C. vallejoi given in brackets): dorsal surface with metallic green reflections (1-as C. mendax; 2-without green reflections); antennae with 10 antennomeres (1-nine antennomeres; 2-as C. mendax: Jhon C. Neita Moreno, personal communication); male protarsomere I greatly enlarged (1-slightly enlarged; 2-as C. mendax); male metafemur slightly enlarged and approximately 2.1-2.4 times longer than wide (1 and 2-greatly enlarged and approximately 1.5-1.7 times longer than wide; Figs. 13, 15, 17); male metatarsus somewhat filiform (1-somewhat moniliform; 2-as C. mendax); male pygidium with hair-like setae (1-with scale-like setae; 2-as C. mendax); females with long gonocoxite (Figs. 23-25; 1-wide; 2-comma-like).

\section{Key to Compsodactylus species}

1. Metatibia apically with a single spine projecting parallel to the length of the metatibia or with a single, thickened, perpendicular

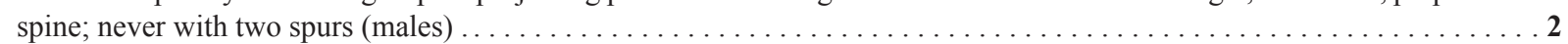

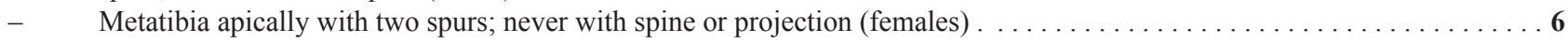

2. Metatibial spine long, thin, projecting parallel to the length of the metatibia (Figs. 9-12) $\ldots \ldots \ldots \ldots \ldots \ldots \ldots \ldots$ Metatibial spine truncate or pointed, thick, sometimes twisted, projecting perpendicular to the length of the metatibia (Figs.

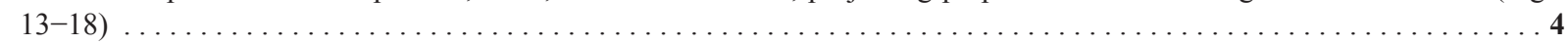

3. Elytral striae strongly and regularly punctate; metatibia gradually enlarged; Argentina (Catamarca, Córdoba, Misiones, Salta, Tucumán $\ldots \ldots \ldots \ldots \ldots \ldots \ldots \ldots \ldots \ldots \ldots \ldots \ldots \ldots \ldots \ldots \ldots \ldots \ldots \ldots \ldots \ldots \ldots \ldots \ldots \ldots$ argentinus $($ Moser, 1919) Elytral striae shallowly and irregularly punctate; metatibia abruptly enlarged in proximal third; Bolivia (Cochabamba, Santa

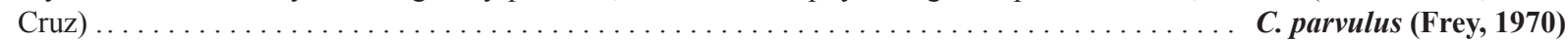

4. Clypeus anteriorly enlarged and medial area glabrous (Fig. 4); metafemur slightly enlarged and about 2.1-2.4 times longer than 
wide (Fig. 15); Peru (Lima)

C. mendax Fuhrmann \& Smith, new species Clypeus trapezoid and without glabrous area; metafemur of males greatly enlarged and about 1.5-1.7 times longer than wide (Figs. 13, 17)

5. Antennae with 9 antennomeres; pronotum and elytra with metallic green reflection; apex of protarsomere I slightly wider than apex of protarsomere II, pygidium with scale-like setae; Peru (Apurímac) . . . . . . . . . . . . C. martinezi (Frey, 1972) Antennae with 10 antennomeres; dorsal surface without metallic green reflection; apex of protarsomere I approximately 2 times wider than apex of protarsomere II; pygidium of males with hair-like setae; Peru (La Libertad)

C. vallejoi Figueroa \& Neita-Moreno, 2019

6

Pronotum and elytra with distinct metallic green reflections.

..........................

- Pronotum and elytra without metallic green reflections $\ldots \ldots \ldots \ldots \ldots \ldots \ldots \ldots \ldots \ldots \ldots \ldots \ldots \ldots . \ldots \ldots$

7. Antennae with 9 antennomeres; pygidium yellowish brown or dark brown; Peru (Apurímac) . . . C. martinezi (Frey, 1972)

- $\quad$ Antennae with 10 antennomeres; pygidium black with metallic reflections; Peru (Lima) . ...

C. mendax Fuhrmann \& Smith, new species

8.

Antennae with 10 antennomeres; elytra yellowish brown with black margins; Peru (La Libertad)

C. vallejoi Figueroa \& Neita-Moreno, 2019

Elytra with 9 antennomeres; elytra yellowish brown or brown and margins not darker than disc $\ldots \ldots \ldots \ldots \ldots \ldots \ldots \ldots 9$

9. Elytral striae weakly and irregularly punctate; Bolivia (Cochabamba, Santa Cruz)

C. parvulus (Frey, 1970)

Elytral striae distinctly and regularly punctate; Argentina (Catamarca, Córdoba, Misiones, Salta, Tucumán)

C. argentinus (Moser, 1919)
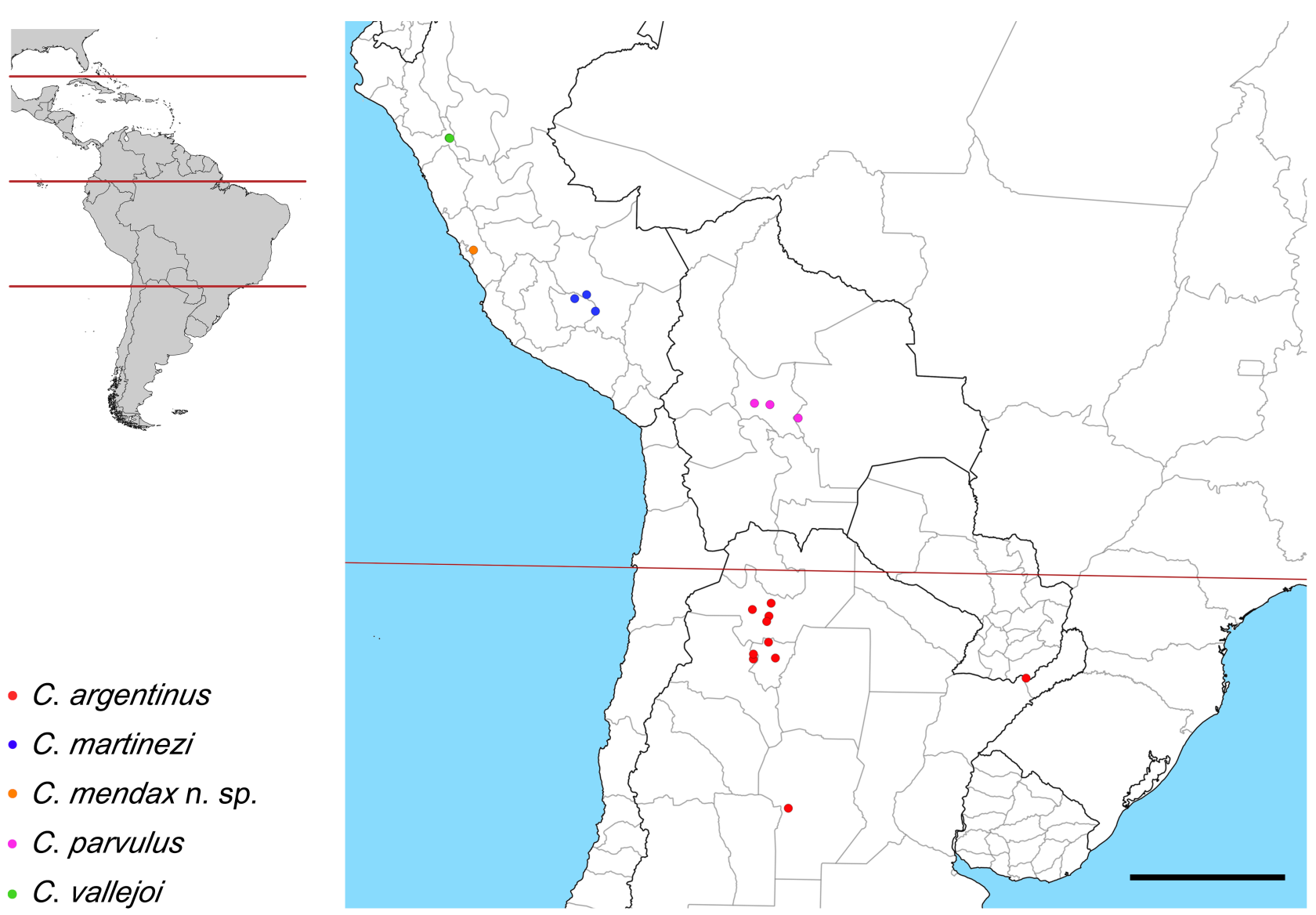

- C. argentinus

- C. martinezi

- C. mendax n. sp.

- C. parvulus

- C. vallejoi

FIGURE 26. Compsodactylus, map of species records. Scale $=500 \mathrm{~km}$.

\section{Acknowledgements}

We thank Paul Skelley and Kyle Schnepp for access and assistance with the Florida State Collection of Arthropods specimens and Jhon C. Neita-Moreno (Instituto de Investigaciones de Recursos Biológicos Alexander von Humboldt, Colombia) for additional information on C. vallejoi characters. Thanks to Sônia A. Casari (Museu de Zoologia da Universidade de São Paulo) for supervision of J.F., to the Beaty Centre for Species Discovery at the Canadian Museum of Nature for the visiting scientist award to J.F., and to Lory Beaudoin and Robert Anderson for facilitating the visiting scientist award. 


\section{References cited}

Beutel, R.G. \& Lawrence, J.F. (2005) Coleoptera, morphology. In: Beutel, R.G. \& Leschen, R.A.B. (Eds.), Handbook of Zoology. A Natural History of Phyla of the Animal Kingdom. Vol. IV. Arthropoda: Insecta. Part 39. Coleoptera, beetles. Vol. 2. Morphology and Systematics (Elateroidea, Bostrichiformia, Cucujiformia partim). Walter de Gruyter, Berlin, pp. 23-28. https://doi.org/10.1515/9783110904550.23

Figueroa, L. \& Neita-Moreno, J.C. (2019) A new Compsodactylus Fuhrmann (Coleoptera: Scarabaeidae: Melolonthinae) from Peru. Zootaxa, 4560 (3), 587-591. https://doi.org/10.11646/zootaxa.4560.3.12

Fuhrmann, J. (2012) Compsodactylus, a new South American genus with one new species and two new combinations (Coleoptera: Scarabaeidae: Melolonthinae). Zootaxa, 3577 (1), 43-57. https://doi.org/10.11646/zootaxa.3577.1.2

Fuhrmann, J. (2019) Taxonomy of Neotropical genera Compsodactylus and Dasyus and notes on claw movement in Macrodactylini (Coleoptera: Scarabaeidae: Melolonthinae). Zootaxa, 4679 (1), 139-163. https://doi.org/10.11646/zootaxa.4679.1.9

Lawrence, J.F., Beutel, R.G., Leschen, R.A.B. \& Slipinski, A. (2010) Glossary of morphological terms. In: Leschen, R.A.B., Beutel, R.G. \& Lawrence, J.F. (Eds.), Handbook of Zoology. A Natural History of Phyla of the Animal Kingdom. Vol. IV. Arthropoda: Insecta. Part 39. Coleoptera, beetles. Volume 2: Morphology and Systematics (Elateroidea, Bostrichiformia, Cucujiformia partim). Walter de Gruyter, Berlin, pp. 9-20.

https://doi.org/10.1515/9783110911213.9 